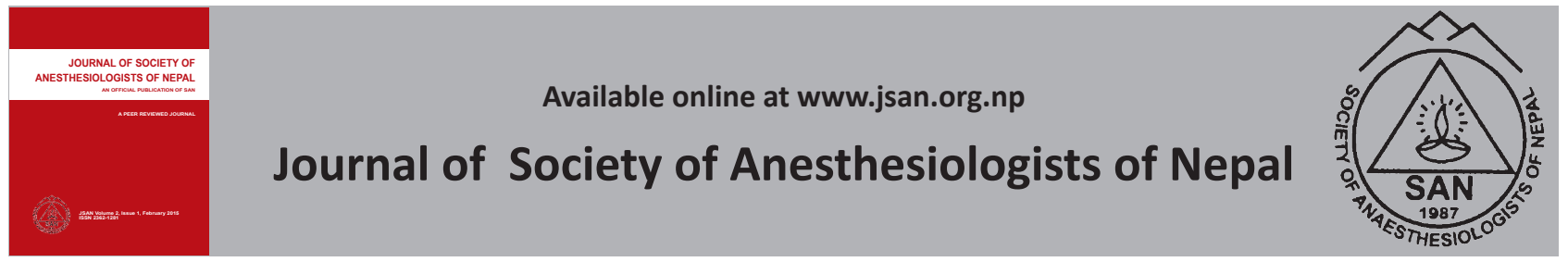

Letter to the editor

\title{
Inadvertent arterial cannulation during intravenous cannulation of the cephalic vein
}

\author{
Parineeta Thapa, Balkrishna Bhattarai \\ BP Koirala Institute of Health Sciences, Dharan, Sunsari, Nepal
}

A R T I C LE I N F O
Article history
Received 06.02 .2015
Accepted 08.02 .2015
Published 26.02 .2015
(C) Authors retain copyright
and grant the journal right
of first publication with the
work simultaneously licensed
under a Creative Commons
Attribution License that allows
others to share the work with
an acknowledgment of the
work's authorship and initial
publication in this journal.

To the Editor,

Cephalic vein in the wrist is a common choice for peripheral venous cannulation due to easy access and splinting as well as consistent anatomy. Unintentional radial artery cannulation during cephalic venous access over the radial styloid process is unlikely and rare. Here we report such a case while securing venous access.

A 43 year-old lady was planned for total abdominal hysterectomy. The cephalic vein at her wrist was made prominent by manual compression and the skin was prepared with antiseptic solution. Cannulation of the vein over the right radial styloid process was started with an $18 \mathrm{G}$ cannula. The needle was withdrawn and the cannula advanced once blood was seen in the flash back chamber. Intravenous fluid transfusion set was connected. It was noted that there was a back flow of bright red blood into the transfusion set rather than free flow of fluid into the vein. We suspected arterial cannulation. On palpation, the tip of the cannula was felt anteromedially where a distinct arterial pulse was palpable (Figure 1). The cannula was removed and compression was applied over the puncture site to prevent bleeding and hematoma. No further problems like pain, distal ischemia or hematoma were noted in the limb. Anaesthesia and surgery were commenced after securing a new intravenous line in her left hand. At the insertion site of the cannula a distinct arterial pulse could be palpated revealing the presence of an artery near the cephalic vein.

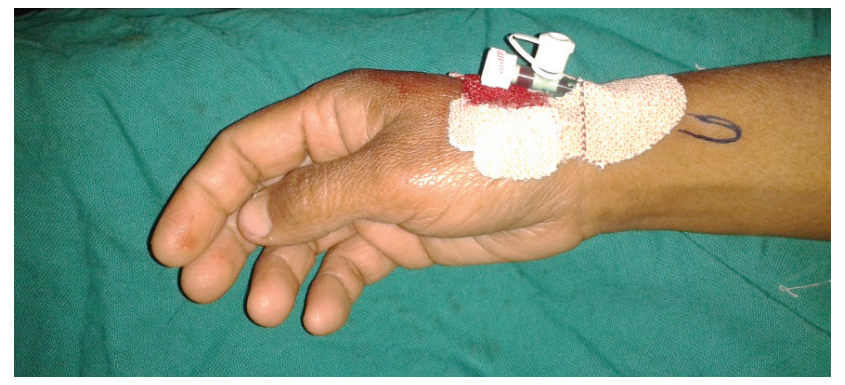

Figure 1: Cannula in the wrist with its tip (marked) anteromedially
Inadvertent arterial cannulation during central venous cannulation is a common complication but is rare during peripheral venous cannulation. A few incidences have been reported during cephalic, basilic, cubital and saphenous vein cannulation. The most likely reason of arterial puncture during cephalic vein cannulation at the level of wrist is the presence of superficial radial artery. Normally the radial artery runs several millimeters deeper than the cephalic vein, so the risk of arterial cannulation is rare. ${ }^{1}$ But in 0.5 to $1 \%$ of individuals, there is superficial radial artery, where the radial artery at the level of wrist crosses over the tendons which define the snuff box, rather than

Corresponding author:

Parineeta Thapa, MD, Assistant Professor,

Department of Anaesthesiology and Critical Care, B. P. Koirala Institute of Health Sciences,

Dharan, Sunsari, Nepal, Email: parithapa2002@yahoo.com, Telephone-+9779841278616 
running deep to it. ${ }^{2}$ Unidentified arterial cannulation and injection of drugs into an artery can cause devastating complications like arterial thrombosis and ischemia of the limb distal to the injection site. Need for thrombectomy and surgical repair of the artery has also been reported. ${ }^{3}$ Anticipation and early identification of this situation is important in preventing further harm to the patient. Use of arterial blood gas analysis and pressure transducer may be required at times when clinical judgement alone may fail, as in cases with hypovolemia. In our case we could trace the tip of the cannula going anteromedially into the direction of radial artery confirming its intraarterial location.

Peripheral venous cannulation is performed after making the vein prominent and possibility of inadvertent arterial cannulation is seldom thought of. Our and similar other cases prompt us to routinely palpate the venipuncture site for arterial pulse prior to venous cannulation to avoid this potentially harmful situation.

\section{References}

1. Lirk P, Keller C, Colvin J, Colvin H, Rieder J, Maurer H, et al. Unintentional arterial puncture during cephalic vein cannulation: case report and anatomical study. Br J Anaesth 2004;92:740-2.

2. Rodriguez-Niedenfuhr M, Vazquez T, Nearn L, Ferreira B, Parkin I, Sanudo JR. Variations of the arterial pattern in the upper limb revisited: a morphological and statistical study, with a review of the literature. J Anat 2001;199:547-66.

3. Beale EW, Behnam A. Injection injury of an aberrant superficial radial artery requiring surgical intervention. J Hand Microsurg 2012;4:39-42. 